\title{
The Spatial Homeostasis Hypothesis
}

\author{
Oleg Epstein \\ OOO “NPF “Materia Medica Holding”, 47-1, Trifonovskaya Str., 129272 Moscow, Russia; \\ nauka@materiamedica.ru; Tel.: +7-495-276-1571
}

Received: 12 March 2018; Accepted: 8 April 2018; Published: 10 April 2018

\begin{abstract}
From studies on the effects of "high dilutions" on organisms, it was found that their administration induces a delicate physiological (molecular and cellular) response. Occasionally, physiological reactions can become atypical (pathological) individual reactions. To resolve this paradox, the spatial homeostasis hypothesis has been proposed. It considers pathological processes as tools used by living systems, in order to retain their spatial integrity (symmetry), allowing them to properly reflect the geometry of the surrounding world and thus, to be a part of the evolutionary process. This article addresses an interdisciplinary subject and is aimed at natural scientists (physicists, chemists, and biologists) as well as philosophers.
\end{abstract}

Keywords: released-activity; technology of gradual concentration decrease; high dilutions of medicinal agent; released-active antibodies; biological evolution hypothesis; evolutionary role of pathological processes

\section{Introduction}

Since the 1970s, a large body of experimental work has been amassed, including work carried out in Russia [1-7], which shows that high dilutions no longer containing molecules of the original substance are able to cause a physiological reaction based on molecular-level effects. A number of properties commonly attributed to "high dilutions" have been discovered [8]. Numerous methods have demonstrated that "high dilutions" differ structurally from the intact solvent. These methods have included conductometry [9,10], pH monitoring [9,10], viscometry [10], calorimetry [9], photoluminescence spectroscopy [11], ultraviolet-visible spectrophotometry [12-14], fluorescence microscopy [12], atomic force microscopy [12], infrared spectroscopy [12], Raman spectroscopy [15,16], nuclear magnetic resonance (NMR) relaxometry [17-20], electromagnetic signal detection [21], crystallogenesis studies [22], droplet crystallization [23], NMR spectroscopy [20,24], and dielectric property analysis $[25,26]$. On the basis of these results, a popular perception of the solvent "memory" effect has been formed - the dilutions contain a structured material (dynamic) matrix, which retains information about the eliminated original substance. The majority of authors consider the restructuring of a solvent's hydrogen bonds as the basis for the formation of this matrix [27].

In the middle of the 1990s, we were the first to discover that "high dilution" of a substance exerts a modifying effect on the original substance, both in vivo and ex vivo. In our opinion, this effect underlies the mechanism of action of "high dilutions".

The modifying properties appear during the process of serial dilutions, and in order to emphasize their technogenic nature, the term "released-activity" has been proposed [28]. First of all, we were interested in practical research of the discovered phenomenon, including its molecular mechanisms (for example, [29-32]). Ultimately, our studies lead to the development of a new group of drugs based on "high dilutions" of antibodies: "released-active" antibodies.

Since the 18th century, "high dilutions" of various substances of natural origin have been prescribed individually in traditional therapy, apparently in order to enhance their biological effect 
via immunological hypersensitivity mechanisms. In some cases, this may be accompanied by pathological conditions expressed as intoxication symptoms, as if it were not "high dilutions" of the original substance administered to the organism, but toxic doses [33]. We consider this paradoxical phenomenon a uniquely simple model of pathology, providing the opportunity to get closer towards understanding basic principles underlying the functioning of biological systems.

We have repeatedly approached this theoretical problem [28,34,35], resulting in the development of the "spatial homeostasis hypothesis". It considers pathological processes as a tool used by living systems to retain their spatial integrity (symmetry), allowing them to reflect properly the geometry of the surrounding world and thus, to be a part of the evolutionary process.

\section{2. "High Dilutions" of Substances}

In our concept, we postulate the involvement of certain physical fields and specific resonances into the mechanism of action of "high dilutions". In principle, similar ideas have been repeatedly expressed in scientific reports [36].

The above-mentioned modifying properties of "high dilution" were discovered in the course of our own research developing new drugs. In a series of experiments, animals were co-administered a "high" (either a therapeutic or even toxic) dose of a common drug, such as prednisolone, haloperidol, phenazepam, diclofenac or cyclophosphamide, together with a "high dilution" of the same drug. The results showed that in the presence of its "high dilution", the activity of the drug was positively modified, enhancing pharmacological effects and reducing toxicity [37-48].

Dosage, as commonly understood, is a specific amount of a substance (its portion) that should retain properties of the original substance. However, the terms "low dose" and "dilution" are not appropriate for "high dilutions" that qualitatively differ from the original substance. Thus, we prefer to use the terms "released-active dilutions" or "released-active drugs" [28].

In the presence of an original substance (a pharmacological drug, for example), its released-active (R-A) dilution behaves as an independent material object, whose activity is directed at the same targets in the organism as the original substance.

The mechanism of R-A drug action appears to involve resonance interaction with the target molecule, leading to its conformational change. For example, NMR spectroscopy showed that R-A dilutions of proteins produced by the immune system, namely antibodies to interferon gamma (IFN- $\gamma$ ), alter the conformational state of the proteins' biological target-IFN- $\gamma$ molecules. This facilitates the displacement of equilibrium between the monomeric and dimeric forms of IFN- $\gamma$ towards dimeric form, leading to the increase in the number of IFN- $\gamma$ molecules binding to the IFN- $\gamma$ receptor [28]. Through the positive feedback loop, this leads to an increase in IFN- $\gamma$ expression in vivo [49].

The action of R-A drugs is specific, directed only at the original substance or its in vivo targets. In pharmacology, specificity is a necessary property of any given drug or substance. In addition, R-A drugs cause effects similar to those of low intensity fields. This is exemplified, first and foremost, in their rapid action. The consumption of R-A drugs may, for example, cause instant electroencephalogram (EEG) changes.

The effects of R-A dilutions have a complex, multimodal dependence on the degree of their dilution (i.e., non-monotonic dependence, when maximum activity is observed in certain dilution intervals, separated by the so-called "dead zones"). This fact can be treated as indirect evidence of the R-A essence carrier's finite properties (discrete characteristic). In other words, in a volume of an R-A drug, there is only a certain, finite amount of the R-A activity carrier. At the same time, the complexity of this dependence attests to the fact that the mechanism of the R-A drug action is distinct from classical pharmacokinetic processes, and is closer to that of weak electromagnetic fields.

Individual reactions are one of the mysteries of medicine; so far, their mechanisms remain undetermined. Marked individual reactions have fatal outcomes in $10-20 \%$ of cases, and it is therefore natural to question the biological role of this phenomenon. Two types of experimentally-induced individual hypersensitivity are known to modern medicine: immediate and delayed. Both types have 
a similar feature-the nonspecific (common) nature of the response. Individual reactions observed in everyday medical practice are also common. For example, patients who have an inherent individual sensitivity to any of a number of drugs used in therapy respond with common individual (hyperergic) reactions, in the form of anaphylactic shock or Quincke's edema. Less dangerous individual allergic reactions to a number of allergens are also limited to several types of typical clinical manifestations. Due to the character of individual reactions to substances not processed by multiple dilutions, we postulate that they are protective in nature, and are connected to the organism's attempt to avoid interaction with the substance to which there is an individual sensitivity. It is probable that R-A drugs are safer for the organism, and therefore the organism allows fully-fledged reactions that have a specific character. In persons with high sensitivity to a particular substance, the R-A form may induce individual reactions, which resemble milder versions of those of a toxic dose of the same drug. This is what determines the specificity of individual reactions to highly diluted drugs.

In contrast to the delicate molecular mechanisms, discovered by us, of the modifying properties of R-A dilutions that form the basis of the normal, physiological activity of R-A drugs, the mechanisms causing individual hyperergic reactions are more complex, and cannot be fully explained within the framework of the existing molecular paradigm in medicine. During hyperergic reactions induced by R-A dilutions, a transformation of an "invisible", normal physiological response into pathological symptoms occurs at the molecular level. We consider this transformation a uniquely simple model of disease pathology, providing the opportunity to move closer towards an understanding of principles underlying the functioning of biological systems. It is the study of this model that led us to the introduction of the spatial homeostasis hypothesis.

This subject consists of two interconnected parts: physicochemical (the nature of the R-A carrier), and biological (the mechanisms of R-A drug action in vivo). Here we will review both parts.

\section{The Problem of the Nature of Released-Active Drugs}

As we have mentioned, released-activity is technogenic. Superficially, the dilution technology consists of three components: a reduction in concentration, succussion, and transfer of a small volume of the intermediate product into an intact medium.

Our studies show that modifying qualities are displayed not only by "high" dilutions, which do not contain molecules of the original substance, but also by "low" dilutions, which do. This fact indirectly corroborates that the transformation of the original substance into the R-A form depends not only on the decrease in concentration, but also on external influences. At the beginning of our research, we applied a manual dilution process, accompanying each dilution with succussion. Eventually we automated the process of preparing dilutions, eliminating the operator effect, and also began using microfluidic systems. However, these improvements did not cause any noticeable changes in the results. Since the serial dilution was accompanied with an external mechanical action anyway, it is difficult to come to a conclusion about the importance of succussion as a separate step.

We suggest several approaches to explain the nature of R-A dilutions:

1. Due to the fact that the product of dilution, an R-A drug, is able to influence the original substance, the dilution process draws an association with the feedback principle.

2. R-A drugs also have the ability to exert a modifying effect in vitro. For example, by adding the $\mathrm{R}$-A form of one of the components, we were able to change the rate of chemical reactions, the electrical conductivity of mercury salt, etc. [50]. The modifying influence of R-A forms on the original substance can thereby be conditionally regarded as autocatalysis, which plays a key role in evolutionary chemistry [51].

3. The ability of R-A dilutions to modify properties of the original substance in vitro allowed us to apply other techniques besides spectroscopy (such as enzyme-linked immunosorbent assay, immune-sensory methods, and high performance liquid chromatography) for the evaluation of R-A drugs [29,52]. While developing analytical techniques, we found that common purified water subjected to the process of dilution ("processed" water) acquired new properties that were 
different from the intact water in $\mathrm{pH}$, electrical conductivity, surface tension, speed of sound propagation, and spectral characteristics (data not published).

The obtained results indicate the paramount role that technology plays in the preparation of R-A drugs. "Processed" water contains newly-formed supramolecular ensembles that have emerged as a consequence of the spontaneous association of water molecules. It can be considered both an object of supramolecular chemistry, and also, due to the external influences changing the entropy in the system, a dissipative system. It is possible that the solvent, in the course of technological processing, converts into a new physicochemical state that is likely to be modulated by the original substance. Similar examples are known from the studies of weak electromagnetic fields, which do not themselves carry any information until they are modulated by an external source (noise) and acquire the ability of stochastic resonance [53,54].

4. We consider it possible to use the relativistic approach: the spontaneous transition of the original substance into a new quality could occur in the course of a completely unnatural process, namely through multiple, successive dilutions. Thus, the substance enters a fundamentally new physical environment, and possibly transforms into a new physical form.

5. We must also consider the role of the vehicle and its potential "reaction" to the introduction of RA-drug. We would like to draw your attention to the following two facts. Firstly, it has been shown that application of an R-A drug onto a solid form of lactose alters the lactose's crystal structure. Secondly, when studying R-A drugs, we found their action to be adaptive and normalizing. We believe that, in an effort to preserve its own spatial structure, a liquid or solid vehicle can reject the R-A drug, then spatially adapt to it and acquire a structure altered from that of the intact vehicle. The R-A drug can be considered as a reflection of the original substance's spatial structure, and its administration into the body is indeed a transfer of a certain adaptive program that activates the rapid formation of a mild response.

6. Finally, we recently obtained data showing that not only the substance, but also its associated processes or "functions" can be subjected to multiple dilution technology. It is common knowledge that integrative brain function is accompanied by constant changes in its electrophysiological characteristics, which can be displayed in an EEG. Using a special program, we combined the EEGs of healthy volunteers to create a "perfect" (normal) reference EEG, modulated in terms of the amplitude of the alternating electric current (signal). The modulated signal was then passed through purified water, which was subsequently subjected to the dilution technology. We later discovered that the product obtained as a result of the aforementioned process displayed the principal property of R-A drugs-the ability to influence the original substrate. The product is capable of modifying the EEGs of experimental animals, and this effect determines the product's neurobiological activity. This example may serve as indirect evidence that the mechanisms of multiple dilutions can also be directed toward the frequency-wave spectrum of the original substance molecules.

7. Whichever could be the possible mechanisms of the multiple dilution process, the main feature of its final "product", the R-A form, is the unique property of exerting an influence on the original substance. For this reason, the R-A form cannot be simply its sub-molecular (corpuscular or wave) particle. We conditionally consider the R-A state of a molecule to be supramolecular matrix; the spatial structure and scintillation properties of the molecule of the original substance are preserved within it. These features enable the R-A form to interact resonantly with the original substance that is manifested in its aforementioned conditional "wave" nature.

Overall, we deal with a system that is distributed in space, far from a thermodynamic equilibrium state, and therefore likely to be non-linear. Instead of limiting discussion of the system's states to a reduction in the amount of the original active substance that results from the dilution process, it is plausible to consider a consecutive process, during which the macroscopic states of the system may become permanently changed. Notably, the sequential dilution process is accompanied by active 
mechanical (convective) impacts associated with each succussion. This process maintains the presence of the thermodynamically unbalanced, dynamically-ordered states within the system. In principle, the $\mathrm{R}$-A forms may be viewed as long-lived dissipative structures.

Of course, mechanisms for the appearance of new properties in the dilutions will need to be studied further, in simpler and more "formal" models than the organism itself. We do hope that eventually the problem of released-activity will be of interest to physicists and chemists.

\section{The Concept of the Supramolecular Matrix}

Pharmacologists have traditionally studied the effects of toxic and therapeutic doses of drugs. We have long been accustomed to the fact that a significant number of molecules of a substance do affect molecular processes in the body. Research into the effects of R-A drugs expands our knowledge about the organism activity, and allows us to re-evaluate the principles of biological systems functioning.

The ability of the body to interact with R-A dilutions demonstrates the presence of a supramolecular level of organization in living systems towards which the action of R-A drugs is directed, and upon which molecular reactions to the administration of these drugs develop.

As we have already noted, the effects of R-A drugs are specific. R-A drugs obtained from synthetic and biological substances have a direct effect on the target molecules in the body structurally similar to them, most likely via the resonance mechanism [8] changing their spatial structure, which we have shown to be the trigger mechanism of their action.

It is more difficult to explain the mechanisms of action for highly diluted drugs obtained from natural raw materials, since these R-A preparations do not have target molecules in the organism (e.g., a receptor or enzyme) identical to their structure. If the interplay of any molecule in the body with its R-A form counterpart is considered to be a remote interaction of two geometrically matching structures capable of resonance, then for any R-A drug made from, for example, plant material, there must be a spatial target in the body, structurally corresponding to the drug. Such a target is an evolutionarily predefined supramolecular matrix. The geometric characteristics of this matrix are its essential content (or "essence") that, according to the structure of the matrix, arranges a certain molecular pool of the organism into a "semantic" molecular ensemble. Thus, all molecules in the organism are integrated into structural-functional ensembles. The vital activity of biological systems is predetermined by rigid structural frameworks, according to the laws of symmetry.

\section{Dualistic Species-Individual Symmetry of Biological Systems}

Analysis of the mechanisms of individual reactions led us to the idea that the spatial structure of living systems has a unique, dualistic, species-individual principle of organization. These structures are generally similar in species, yet there are individual ones for each particular organism of a given species. For some reason, the organism responds to all external influences, even those so weak (such as R-A drugs) that they do not threaten the organism's vital functions. In physiology, reactions to such influences are called "reactions to novelty"; when the influences are repeated they weaken or do not form at all [34].

Therefore, the main question of our research is why, in the presence of an individual sensitivity to a particular drug, does the organism behave paradoxically, and transform invisible (asymptomatic) molecular physiological reactions to R-A preparations into pathological reactions accompanied by clinical symptoms? We see the answer to this question in the complex, nonlinear (integral or holographic) structure of the organism's internal space. The organism's functioning is executed in associated conditional spatial planes (the individual- and the species-specific), due to the dualistic species-individual genome organization. Each endogenous molecule expressed by genome has a dualistic, species-individual spatial orientation. It is probably necessary for the organism, in order to perform its vital activity, not only to respond to any external influence, but also to assess it comprehensively. As a result, a unique situation may arise if the spatial structure or "architectonics" of the external factor (influence) and the individual spatial structure of the organism coincide. In this case, 
the spatial image of the external influence does not deviate from the parameters of the conditional individual plane, does not form a coherent image, and cannot be evaluated for foreignness. Therefore, the organism is forced to scale the image up in a way to obtain a complete, "holographic" reflection of the external influence. Holography, from the Greek " $\mathrm{O} \lambda \mathrm{o} \sigma$ ", meaning whole, is a method of obtaining a stable three-dimensional image, a hologram, first proposed by Dennis Gabor in 1948 [55]. A complete image is contained at any point in a hologram, since all the elements of the hologram are spatially connected, due to the interference of optical waves. The holographic principle was applied to biology by Karl Pribram, in order to explain the integrity of perception in any part of the brain [56], and is traditionally used by neurophysiologists.

Thus, the organism's behavior seems paradoxical: for the sake of assessing the external factor, the body is prepared for a hyperergic response, or even to die. Later, we will demonstrate that the suppression of a response to "foreign" is due to higher evolutionary purposes of biological systems. While analyzing the clinical applications of R-A drugs, we also identified the following significant points:

1. Clinical manifestations of a hyperergic reaction, induced by a highly-diluted drug in healthy individuals, can be used as an indication for the individualized prescription of the medication to patients whose disease pattern has the same symptoms. There is, however, one nuance: a single symptom not associated with the other symptoms is not a reliable criterion for prescribing the drug. In other words, the indication for prescription is not just a symptom, but a definite integral complex of symptoms-a syndrome.

2. Individual sensitivity to one or another individually-prescribed R-A drug is empirically determined by phenotypic factors-not by one, but again by a range of associated phenotypic markers (constitutional features, external signs, medical history, character traits, behavioral habits, etc.). Thus, hyperergic reactions to R-A drugs manifest themselves in individually coupled pathological symptoms in patients with individual sensitivity, in the form of a set of phenotypic factors.

We also consider cases of a common "pan-species" array of pathological manifestations. For instance, in order to determine what substance a patient has been poisoned with, doctors take into account not a single, but an entire set of specifically associated symptoms; each one can be found separately in various diseases. In order to preliminarily determine the cause of an infectious disease the whole complex of associated reactions to an external pathogenic factor is also considered.

Thus, we see that pathological manifestations have a species-individual nature of conjugacy. This attests, firstly, to the pre-existence of an organism's species-individual pathological syndrome structure, and secondly, to its integral, holographic spatial structure.

The examples given are important for a deeper understanding of the term "information". In these observations, we obtain information about an external factor: an R-A drug, an infectious agent, or a toxic substance, in the form of signs (symptoms), spatially coupled within the pathological syndrome. We shall return to the idea that information can be "encoded" in spatially-coupled structures later, when considering the role of DNA.

\section{The Evolutionary Postulate}

The similarity in the structural organization of living and inanimate systems that we have identified at the supramolecular level (in the form of pre-existing spatial matrices), the integral species-individual (holographic) and hierarchical principles of the organism's structure are closely related structural and biological phenomena.

We believe that these features indicate the same origin of animate and inanimate natures in the course of prebiotic evolution. We consider the procedure of gradual concentration reduction leading to the creation of the released-active form of the original substance a kind of "dematerialization". We believe that in the course of the material world's prebiotic evolution, the opposite process took 
place-the formation of spatial complexity from a conditional void (vacuum). Evolution is governed by the struggle of opposites-for the right to organize and structure the vacuum according to the spatial and temporal principles inherent in each of the opposites, and their desire to impose their own arrangement algorithm and symmetry principles on all possible spatial guises. If we use the geometric images as visual illustration, evolution could have begun with primary fluctuations in the vacuum, which can be treated conditionally as points. If three points can be united by only one plane, then four primary fluctuations can already be combined into different fractals with their further multiplication via the replication mechanism.

This process of generating spatial complexity led to the formation of supramolecular space, and later, the more familiar three-dimensional space. At the same time, all objects in three-dimensional space, both physical and biological, are a consequence of the materialization or "hypostatization" of supramolecular entities of varying levels of complexity. As a result, all three-dimensional systems are "integrated" into a supramolecular ether. Material events in these systems occur simultaneously in both the three-dimensional space and in the simpler supramolecular dimension.

At a certain stage in the evolutionary struggle of at least two opposites for the assimilation or "fractalization" of the universe on the supramolecular level, two events should have concurred: first, the segmentation or "atomization" of minimum vacuum loci, in order to give them a unique individuality and preservation in each locus of the spatio-temporal principles of organization, a predetermined symmetry common to either of the opposites. Later, the "materialization" of such dually-arranged supramolecular structures led to the emergence of living systems, combining both the individual and the common, or the "pan-species". The hypostatization of dually-organized supramolecular structures resulted in the emergence of polymers, the DNA or RNA (in some viruses) possessing the main evolutionary instrument: the ability to replicate and, as a result, reproduce in biological systems the "correct" evolutionarily-specified spatial organization. In the example of the aforementioned R-A drug created using EEG, we observe that the process of multiple dilutions, the opposite of hypostatization, can be applied not only to molecules, but also to their functions. Together with the polymers, their hereditary features and "potential functions", encoded in the complex fractal spatial-vibrational structure of DNA and RNA, were also transferred into the three-dimensional space. Biological systems are the pinnacle of the evolutionary process, as they possess the individuality of spatial organization, and are capable of reproducing it in future generations. Only living systems have a dualistic species-individual organization that determines the spatio-temporal interconnection of molecular events occurring in biosystems. The organism responds specifically, not only to molecular but also supramolecular external factors. This indicates the integrity of molecular and supramolecular processes in living systems. In turn, any factor affecting the organism has its own unique spatial structure, which the organism evaluates by incorporating into its internal space, leading to an increase in structural complexity. The holographic organization of living beings allows biological systems to perform their primary evolutionarily driving process: to comprehensively and "correctly", according to the evolutionarily specified spatio-temporal principles, reflect reality, and "correctly" make themselves more complex. In doing so, beings continue the evolutionary process on the supramolecular physical "ether" level. In this process, we see a solution to the aforementioned paradox: the evolutionary goal that lies in the reflection of surrounding life is more significant to the organism than its own life. Therefore, death is also an evolutionary factor that limits the incorrect reflection.

The increasing complexity of biological systems leads to an expansion of bonds or "connections", including intermolecular, between the constituent elements of an organism. However, the enormously capacious nonlinear interior space allows stable retention of these bonds, enabling an anti-entropic directionality of vital functions. The increase in complexity in three-dimensional space plays an evolutionary role only if it occurs in living systems. The examples of anti-entropic self-sophistication of non-biological structures used in thermodynamics merely indicate that an evolutionarily conditioned structuredness, preset on a supramolecular level, is present within them. Just as an electron can only occupy a specific orbit, thermodynamic systems, given an entropy change, are also capable of 
transitioning only into predefined stationary states. This predetermination is a consequence of the fractalization of supramolecular space or, simply put, the building-block principle of supramolecular structures' evolutionary assembly. Subsequently, any artificially-created thermodynamic system is stable only if it complies with the following rules: firstly, in the conditional supramolecular plane the system should consist of integrated evolutionarily-formed units. Secondly, it should be harmoniously "embedded" in supramolecular space. It is likely that the "embedding" into the pre-existing supramolecular ether is due to the formation and stability of various ensembles considered by supramolecular chemistry.

\section{The Spatial Homeostasis Hypothesis}

\subsection{Pathological Processes as Adaptive, Evolutionarily Pre-Existing Reactions}

The evolutionary approach allows us to treat pathological processes as adaptive, evolutionarily pre-existing reactions aimed at preserving spatial homeostasis-an integral, dynamic, hierarchical spatial structure of the organism. This enables the structure's main role in the evolutionary process: to "correctly" reflect reality. All events in the body overcome an opposition (inertial resistance), as biological systems are open, in a spatial sense; they also experience a constant "counter-resistance" from the "foreign" opposites on the supramolecular "ethereal" level. Biological objects live as long as they preserve the plasticity of their physiological processes. Plasticity atrophy, due to the inertia of their functioning or external pathogenic exposure, leads to dysregulation, the accumulation of stochastic processes, natural aging, and death. It is well-known that there are no pathological molecules in the body. It is extremely rare that one or another pathology can be determined by changes in a single biochemical or histochemical marker. The specificity of pathological symptoms is determined by the change or "deformation" of the structural-functional organization of certain semantic ensembles of endogenous molecules. Under pathological structural deformation, the body tries to retain its spatial architectonics and common symmetry, in order to continue the evolutionarily significant process of reflection; thus, from an evolutionary viewpoint, the concept of "pathology" is relative. The constant striving towards spatial homeostasis determines the directionality of a biosystem's functioning, integrates its vital functions, and systemically defines the adaptive, multi-parameter [57] useful result. This result, according to the theory of functional systems, is the factor that determines functioning [58]. To shed further light on this concept, we note that the activity of an organism is structured or determined on the supramolecular level and is, depending on the situation, constantly directed towards whichever pre-existing or "stationary" structural-functional state the integrated parameters of the organism are "closest" to at a given moment. Huge numbers of biochemical, functional, and behavioral parameters of vital activity are constantly synchronized and "adjusted" towards a pre-existing, harmonious state of equilibrium. The preservation of structural integrity, even within the conditional pathological organization, allows biological systems to maintain the integrity of regulation up to a certain point.

\subsection{Pharmacotherapy as a Tool to Retain Symmetry of the Organism}

According to our hypothesis, pharmacotherapy results in a spatial substitution of a pathological symptom. As we have already shown, R-A drugs have a direct effect on spatially identical, complementary target molecules, or pathologically altered spatial ensembles (disease syndromes). At regular doses, however, pharmacological drugs have a direct effect on the structure of the pathological symptom. Flexible processes in the organism, both physiological and biochemical, initiated by the introduction of a pharmacological drug, are spatially coupled with their "subtle" structure: at the moment of reaction to a medication, new stable structural-functional relations appear in the body. What takes place is a "recoding" of the drug's molecular structure into the structure of a semantic molecular ensemble. The match of the drug's flexible reflection with a spatially identical organization of the pathological symptom leads to the disruption of the pathological balance, and 
initiates a spatial rearrangement of the symptom. By way of analogy with Ehrlich's "magic bullet" [59], we can consider the spatial structure of the drug determining tropism for the pathological symptom as its "magic ratio". A tropism is a result of the reflection of an external influence, preceded by distinguishing it as "self" vs. "non-self" by the immune system.

Except for tropism, classical pharmacological drugs should have a dose that is sufficient for a therapeutic effect. The evolutionarily significant desire to maintain their own spatial structure is characteristic of all three-dimensional objects, including medicinal drugs. Therefore, when distributed in bodily fluids, the drug strives to maintain its spatial identity. Starting with a certain critical, sub-toxic dose of the drug, the process of reflecting the drug may be accompanied by the threat of losing the organism's spatial integrity and symmetry. As a result, the organism is forced to respond with an adaptive reaction, in the form of an additional rearrangement of the drug's "image" in order to preserve its own original, evolutionarily-determined spatial parameters within its boundaries. Thus, it is not the drug that treats, but the adaptive, protective reaction to the drug, and the therapeutic dose must be, a priori, sub-toxic. R-A forms, as we have already noted, are an adaptive response to the structure of the original substance that has been already formed in the vehicle, either a solvent or lactose. This is exactly what determines the mild nature of their action.

\section{The Formation of Spatial Complexity and Its Control}

\subsection{The Role of DNA}

Long before the discovery of the role of DNA, the famous Russian biologist Alexander Gurwitsch assumed that the spatial orientation of molecular-cellular processes in embryogenesis (the formation and development of the embryo) was determined by the morphogenetic or biological field generated by chromatin [60]. Unlike Gurwitsch, we believe that the genome does not generate a new physical entity, a so-called "field". Instead, the genome integrates the organism into the supramolecular "ether", which provides the structural foundation and directionality for embryogenesis.

We have always been surprised by the simplicity of the process of multiple reductions in concentration. This leads to a spontaneous transition into a new physicochemical state-the transformation of a complex three-dimensional spatial structure into a simpler, supramolecular one. Analogous to this observation, we believe that the opposite action is also possible: the formation of an organism's spatial complexity by a DNA molecule, via direct transmission of spatially-coupled DNA self-oscillations into the surrounding matrix. This process leads to the structuring of the organism's matrix, which is enough to transfer hereditary features into it. Hereditary information is implemented by the unique holographic coupling of events in the biological system at every level of its organization, and must therefore be stored in the DNA, in accordance with the holographic principle.

Earlier, when analyzing the pathological syndrome, we came to the conclusion that it is an example of the spatial coupling of markers that carry information about an external factor affecting the organism. Therefore, it can be assumed that the carrier of hereditary information is not so much the primary sequence of nucleotides in DNA, but rather the spatial or "holographic" organization of the whole DNA molecule (including its non-coding part, which constitutes up to 98\%) [61,62], which is unique to each organism and is defined by the primary structure.

All hereditary markers are coupled and inseparable. As a result, a single novel mutation cannot lead to the appearance of a fundamentally new isolated improvement or "feature" without a parallel increase of the species' entire genome complexity; therefore, a single mutation does not have any evolutionary significance. For the same reason, there is no evolutionary significance in natural selection, which a priori cannot support a single useful marker, and is merely evidence of the interspecies struggle for survival.

The DNA passed from generation to generation is capable, in its fractal-vibrational structure, of preserving traits common to a species and, per se, ensures the "connection" of a new organism to the evolutionarily-developed pan-species' spatial supramolecular matrix. Moreover, the constant 
increase in the spatial complexity of the organism during each individual's life, via the feedback mechanism, also leads to an increase in complexity of the DNA's spatial structure, without changes to its primary structure. This is similar to the concept of "jumping genes", or transposable elements [63], and underlies epigenetic inheritance.

The appearance of new life is preceded each time by the remodeling of the DNA's three-dimensional structure, resulting in the formation of a new, species-individual spatial coupling of DNA molecule parts that is unique to each organism. Therefore, even in the vegetative reproduction of plants, which is not accompanied by the meiotic recombination of genes, the newly-formed plants are phenotypically different from the maternal ones. During sexual reproduction, the zygote that appears after fertilization initiates not only a sequence of mitotic divisions, but also a sufficiently lengthy process of individual-specific DNA spatial restructuring, determining the directionality, and ordering of all molecular and cellular events during embryogenesis. The possibility of artificial induction of immune tolerance in early ontogeny suggests that this process is lengthy, and the integral spatial structure of the future organism is not formed overnight. Restructuring of DNA molecule spatial architectonics begins with the pan-species spatial interactions, established on a supramolecular level at the early stages of evolution, followed by the interactions established at the later stages. Consequently, the stages of species evolution in condensed form are recapitulated in the development of an individual embryo.

\subsection{The Spatial Complexity Control}

The genome not only forms the spatial complexity of the organism, but also controls the "proper" functioning of the organism using only $2 \%$ of the DNA sequences, which code for proteins. These molecules, having a more complex three-dimensional structure than DNA, are the primary genetic regulators of the organism's functioning, as they control less spatially-complex ionic and molecular processes. Each protein has a unique set of self-oscillations, in accordance with its species-individual structure. This results in proteins acquiring the ability to structure a liquid locus in the organism and, as such, monitor the activity of the organism at a certain "level" of its hierarchical organization. It is a well-known fact that the quantity of proteins or polypeptides is excessive in terms of functionality. For example, many neuropeptides have an overlapping physiological activity, which emphasizes their designated role mostly as controllers.

In the process of life, native proteins and peptides can acquire a spatial organization foreign to the organism, and therefore undergo secondary genetic control using the potential of the immune system. Due to the fact that all proteins and polypeptides have an integral holographic structure for identifying their foreignness to the immune system, it is sufficient to estimate the spatial organization of just a small portion of these molecules (antigenic determinant): an epitope containing only 6-12 amino-acid residues. Specialized proteins, antibodies, or T-lymphocyte receptors that are involved in the regulation of all bodily functions (and anti-infectious immunity if necessary) become engaged in the specific identification of an epitope.

This process is so crucial for the organism that an important genetic exception has been made for lymphocytes: they are the only cells in the body where mutations and rearrangements of special variable regions (V gene segments) occur. In our view, these mutations and rearrangements are induced by a change in the spatial complexity of the organism, leading to the emergence of various lymphocyte clones and pools of natural antibodies.

To control spatial complexity, the organism also uses the principle of comparing its own peptides with the "standards" of spatial individuality that are retained in the molecules of the major histocompatibility complex (MHC). Peptides are fitted into special antigen-binding grooves of the MHC molecules, where they are surveyed by T-lymphocyte receptors, and by the intensity of deviations from the organism's spatial norms are recognized either as "self" or "non-self". Significant deviations of the organism's molecules from the spatial norm elicit autoimmune reactions directed, like any pathological processes, towards the preservation of spatial homeostasis. 
The proposal we made concerning the immunological control of spatial complexity is close to Frank Burnet's idea that the main role of the immune system is to maintain genetic integrity of the organism during ontogenesis [64]. An organism's use of the enormous potential of the immune system in order to control spatial complexity testifies to its evolutionary significance.

\section{Conclusions}

Biological model analysis of the effects of released-active drugs allowed us to make the bold assumption that the organism's functioning is determined by events occurring not only on a molecular level, but also on a supramolecular level, and that functioning is governed by the evolutionarily-significant process of reflecting the surrounding world.

We turned to the problem of evolution primarily in order to solve the paradox we had uncovered. Meanwhile, we did not address some important questions, the answers to which (if the concept can withstand the criticism) can be given only by specialists, primarily geneticists, geochemists, and paleontologists. One question is about the evolutionary timeline: did the species appear relatively simultaneously (in terms of geological time), or was this process successive? Another question is to what extent has the postulated reflection of reality by biological systems actually influenced the emergence of species? Was the information reflected in the supramolecular ether used only for the infinitely continuing process of the ether's proper structuring? Or was there a "cosmic Lamarckism" - a hypostasis of new species, more adapted to the changed environmental conditions on the basis of the reflected information, including that of the constantly occurring geological and ecological changes on the Earth?

These and other issues raised in the article are interdisciplinary, relevant to various areas of natural sciences and, to a certain extent, philosophy. In this regard, we purposely simplified the biological aspects and intentionally used more general terms. Unlike biophysicists, we did not address such an important aspect as the energy "supply" of self-organization mechanisms [65]. Despite the complexity of this interdisciplinary article, we hope it will attract the attention of both theorists and practitioners alike, and in time can lead to a deeper understanding of the physicochemical mechanisms of the sequential dilution process and the application of the R-A phenomenon in various fields.

Acknowledgments: This work is supported by OOO "NPF "MATERIA MEDICA HOLDING". The statements of this review have been partly published in 'Uspehi fiziologicheskih nauk'. The full reference: Epstein, O.I. The phenomenon of release activity and the hypothesis of 'spatial' homeostasis. Uspehi fiziologicheskih nauk, 2013, 44(3), 54-76.

Author Contributions: Oleg Epstein wrote the paper.

Conflicts of Interest: Oleg Epstein is a founder of the OOO "NPF "MATERIA MEDICA HOLDING", which produces and markets drugs based on the released-active antibodies. The author declare no other conflict of interest.

\section{References}

1. Shellam, G.R.; Nossal, G.J. Mechanism of induction of immunological tolerance IV. The effects of ultra-low doses of flagellin. Immunology 1968, 14, 273-284. [PubMed]

2. Bonamin, L.V.; Cardoso, T.N.; de Carvalho, A.C.; Amaral, J.G. The use of animal models in homeopathic research-a review of 2010-2014 PubMed indexed papers. Homeopathy 2015, 104, 283-291. [CrossRef] [PubMed]

3. Bellavite, P.; Signorini, A.; Marzotto, M.; Moratti, E.; Bonafini, C.; Olioso, D. Cell sensitivity, non-linearity and inverse effects. Homeopathy 2015, 104, 139-160. [CrossRef] [PubMed]

4. Endler, P.C.; Schulte, J.; Stock-Schroeer, B.; Stephen, S. “Ultra High Dilution 1994” revisited 2015-The state of follow-up research. Homeopathy 2015, 104, 223-226. [CrossRef] [PubMed]

5. Davenas, E.; Poitevin, B.; Benveniste, J. Effect on mouse peritoneal macrophages of orally administered very high dilutions of silica. Eur. J. Pharmacol. 1987, 135, 313-319. [CrossRef] 
6. Fortes, Z.B.; Scivoletto, R.; Garcia-Leme, J. Endothelin-1 induces potent constriction of lymphatic vessels in situ. Eur. J. Pharmacol. 1989, 170, 69-73. [CrossRef]

7. Burlakova, E.B.; Grechenko, T.N.; Sokolov, E.N.; Terekhov, S.F. Vliyanie ingibitorov radikalnyh reakcij okisleniya lipidov na elektricheskuyu aktivnost izolirovannogo nejrona vinogradnoj ulitki. Biofizika 1986, 31, 921-923. [PubMed]

8. Burlakova, E.B.; Konradov, A.A.; Maltseva, E.L. Dejstvie sverhmalyh doz biologicheski aktivnyh veshchestv i nizkointensivnyh fizicheskih faktorov. Khim. Fiz. 2003, 22, 21-40.

9. Elia, V.; Elia, L.; Marchettini, N.; Napoli, E.; Niccoli, M.; Tiezzi, E. Physico-chemical properties of aqueous extremely diluted solutions in relation to ageing. J. Therm. Anal. Calorim. 2008, 93, 1003-1011. [CrossRef]

10. Konovalov, A.I. Obrazovanie nanorazmernyh molekulyarnyh ansamblej v vysokorazbavlennyh vodnyh rastvorah. V. RAN 2013, 83, 1076-1082.

11. Lobyshev, V.I.; Tomkevich, M.S.; Petrushanko, I.Y. Eksperimentalnoe issledovanie potencirovannyh vodnyh rastvorov. Biofizika 2005, 50, 464-469. [PubMed]

12. Elia, V.; Ausanio, G.; Gentile, F.; Germano, R.; Napoli, E.; Niccoli, M. Experimental evidence of stable water nanostructures in extremely dilute solutions, at standard pressure and temperature. Homeopathy 2014, 103, 44-50. [CrossRef] [PubMed]

13. Klein, S.D.; Wolf, U. Comparison of homeopathic globules prepared from high and ultra-high dilutions of various starting materials by ultraviolet light. Complement. Ther. Med. 2016, 24, 111-117. [CrossRef] [PubMed]

14. Wolf, U.; Wolf, M.; Heusser, P.; Thurneysen, A.; Baumgartner, S. Homeopathic preparations of quartz, sulfur and copper sulfate assessed by UV-spectroscopy. Evid. Based Complement. Altern. Med. 2011, 2011, 692798. [CrossRef] [PubMed]

15. Rao, M.L.; Roy, R.; Bell, I. Characterization of the structure of ultra dilute sols with remarkable biological properties. Mater. Lett. 2008, 62, 1487-1490. [CrossRef] [PubMed]

16. Weingärtner, O. Homeopathic Potencies: Wish and Reality in the Search for the Therapeutically Active Component; Springer: Berlin, Germany, 1992.

17. Demangeat, J.L. Gas nanobubbles and aqueous nanostructures: The crucial role of dynamization. Homeopathy 2015, 104, 101-115. [CrossRef] [PubMed]

18. Weingärtner, $\mathrm{O}$. What is the therapeutically active ingredient of homeopathic potencies? Homeopathy 2003, 92, 145-151. [CrossRef]

19. Demangeat, J.L. NMR water proton relaxation in unheated and heated ultrahigh aqueous dilutions of histamine: Evidence for an air-dependent supramolecular organization of water. J. Mol. Liq. 2009, 144, 32-39. [CrossRef]

20. Sukul, A.; Sarkar, P.; Sinhababu, S.P.; Sukul, N.C. Altered solution structure of alcoholic medium of potentized Nux vomica underlies its antialcoholic effect. Br. Homoeopath. J. 2000, 89, 73-77. [CrossRef]

21. Montagnier, L.; Aissa, J.; Ferris, S.; Montagnier, J.L.; Lavalléee, C. Electromagnetic signals are produced by aqueous nanostructures derived from bacterial DNA sequences. Interdiscip. Sci. Comput. Life Sci. 2009, 1, 1-90. [CrossRef] [PubMed]

22. Zhdanova, O.B.; Viacheslavovich, S.I.; Martusevich, A.K.; Artese, F. Crystallogenesis of bioliquid in the homoeopathy. Int. J. High Dilution Res. 2012, 11, 118-119.

23. Kokornaczyk, M.O.; Baumgartner, S.; Betti, L. Polycrystalline structures formed in evaporating droplets as a parameter to test the action of Zincum metallicum 30c in wheat seed model. Homeopathy 2016, 105, 173-179. [CrossRef] [PubMed]

24. Tiezzi, E. NMR evidence of a supramolecular structure of water. Ann. Chim. 2003, 93, 471-476. [PubMed]

25. Maity, T.; Ghosh, D.; Mahata, C.R. Effect of dielectric dispersion on potentised homeopathic medicines. Homeopathy 2010, 99, 99-103. [CrossRef] [PubMed]

26. Chatterjee, A.; Kumar Paul, B.; Kar, S.; Das, S.; Basu, R.; Bhar, D.S.; Nandy, P.S. Effect of ultrahigh diluted homeopathic medicines on the electrical properties of PVDF-HFP. Int. J. High Dilution Res. 2016, 15, 10-17.

27. Drozdov, S.V.; Vostrikov, A.A. Osobennosti stroeniya i energii malyh klasterov vody. Lett. J. Tech. Phys. 2006, $26,81-86$.

28. Epstein, O.I. [The phenomenon of release activity and the hypothesis of "spatial" homeostasis]. Uspekhi Fiziol. Nauk 2013, 44, 54-76. 
29. Don, E.; Farafonova, O.; Pokhil, S.; Barykina, D.; Nikiforova, M.; Shulga, D.; Borshcheva, A.; Tarasov, S.; Ermolaeva, T.; Epstein, O. Use of piezoelectric immunosensors for detection of interferon-gamma interaction with specific antibodies in the presence of released-active forms of antibodies to interferon-gamma. Sensors 2016, 16, E96. [CrossRef] [PubMed]

30. Gorbunov, E.A.; Nicoll, J.; Kachaeva, E.V.; Tarasov, S.A.; Epstein, O.I. Subetta increases phosphorylation of insulin receptor $\beta$-subunit alone and in the presence of insulin. Nutr. Diabetes 2015, 5, e169. [CrossRef] [PubMed]

31. Gorbunov, E.A.; Ertuzun, I.A.; Kachaeva, E.V.; Tarasov, S.A.; Epstein, O.I. In vitro screening of major neurotransmitter systems possibly involved in the mechanism of action of antibodies to S100 protein in released-active form. Neuropsychiatr. Dis. Treat. 2015, 11, 2837-2846. [CrossRef] [PubMed]

32. Nicoll, J.; Gorbunov, E.A.; Tarasov, S.A.; Epstein, O.I. Subetta treatment increases adiponectin secretion by mature human adipocytes in vitro. Int. J. Endocrinol. 2013, 2013, 1-4. [CrossRef] [PubMed]

33. Bellavite, P.; Conforti, A.; Piasere, V.; Ortolani, R. Immunology and homeopathy. 1. Historical background. Evid. Based Complement. Altern. Med. 2005, 2, 441-452. [CrossRef] [PubMed]

34. Epstein, O.I.; Vorob'eva, T.M.; Berchenko, O.G.; Garbuzova, S.N.; Geiko, V.V.; Garmash, T.I.; Titkova, A.M. Informational and Ontological Models of Adaptation; Epstein, O.I., Ed.; IMPE: Moscow, Russia, 1997; p. 166.

35. Epstein, O.I. Regulatory activity of ultralow doses. Bull. Exp. Biol. Med. 2003, 135 (Suppl. 7), 8-13. [CrossRef] [PubMed]

36. Blumenfeld, L.A. Ponyatiye konstruktsii v biologicheskoy fizike. K voprosu o mekhanizme deystviya sverkhmalykh doz. Russ. J. Gen. Chem. 1999, 43, 15-20.

37. Epstein, O.I.; Voronina, T.A.; Molodavkin, G.M.; Belopol'skaya, M.V.; Kheyfets, I.A.; Dugina, J.L.; Sergeeva, S.A. Study of bipathic effect of phenazepam. Bull. Exp. Biol. Med. 2007, 144, 536-538. [CrossRef] [PubMed]

38. Epstein, O.I.; Vorob'eva, T.M.; Geiko, V.V.; Berchenko, O.G. Psychoactive compounds and their antibodies: Effect on self-stimulation of the lateral hypothalamus in morphinized rats. Bull. Exp. Biol. Med. 2003, 135 (Suppl. 7), 132-133. [CrossRef] [PubMed]

39. Vorob'eva, T.M.; Berchenko, O.G.; Geiko, V.V.; Kolyadko, S.P.; Bevzyuk, D.A.; Pan, I.R.; Epstein, O.I. Effect of potentiated antibodies to morphine on behavioral reactions in rats with morphine dependence. Bull. Exp. Biol. Med. 2003, 135 (Suppl. 7), 34-35. [CrossRef] [PubMed]

40. Pavlov, I.F.; Epstein, O.I. Morphine and Antibodies to $\mu$-Opiate Receptors in Ultralow Doses: Effect on Oxygen Consumption. Bull. Exp. Biol. Med. 2003, 135 (Suppl. 7), 137-139. [CrossRef] [PubMed]

41. Pavlov, I.F.; Epstein, O.I.; Shtark, M.B. Behavioral Effects of Potentiated Antibodies to Morphine and $\mu$-Opioid Receptors during Withdrawal Syndrome. Bull. Exp. Biol. Med. 2003, 135 (Suppl. 7), 29-31. [CrossRef] [PubMed]

42. Titkova, A.M.; Epstein, O.I. Effect of Preparation from Potentiated Ethanol on the Content of Biogenic Monoamines and Metabolism of Ethanol in Tissues of Rats during Alcoholization. Bull. Exp. Biol. Med. 2003, 135 (Suppl. 7), 36-38. [CrossRef] [PubMed]

43. Epstein, O.I.; Zhavbert, E.S.; Dugina, J.L.; Pronina, A.V.; Zueva, E.P.; Amosova, E.N.; Krylova, S.G.; Razina, T.G. [Eksperimentalnoe issledovanie fenomena bipatii na primere prednizolona]. Vestnik VolgGMU 2013, 1, 34-36.

44. Sakat, S.S.; Kamaraj, M.; Demidchenko, Y.O.; Gorbunov, E.A.; Tarasov, S.A.; Archna, M.; Epstein, O.I. Release-Active Dilutions of Diclofenac Enhance Anti-inflammatory effect of Diclofenac in Carrageenan-Induced Rat Paw Edema Model. Inflammation 2014, 37, 1-9. [CrossRef] [PubMed]

45. Voronina, T.A.; Belopolskaya, M.V.; Kheyfets, I.A.; Dugina, J.L.; Sergeeva, S.A.; Epstein, O.I. Study of bipathic effect of haloperidol. Bull. Exp. Biol. Med. 2008, 145, 620-622. [CrossRef] [PubMed]

46. Amosova, E.N.; Zueva, E.P.; Razina, T.G.; Krylova, S.G.; Shilova, N.V.; Epstein, O.I. Potentiated cyclophosphane: Experimental study of the effect on tumor development and efficiency of cytostatic therapy. Bull. Exp. Biol. Med. 2003, 135 (Suppl. 7), 107-110. [CrossRef] [PubMed]

47. Petrov, V.I.; Kheyfets, I.A.; Bugaeva, L.I.; Lebedeva, S.A.; Epstein, O.I. [Study of bipathy phenomenon on the example of diclofenac acute toxicity]. In Proceedings of the XVIII Russian National Congress 'Chelovek i Lekarstvo', Moscow, Russia, 11-15 April 2011; p. 470. 
48. Epstein, O.I.; Sergeeva, S.A.; Dugina, Y.L.; Andrianov, V.V.; Gainutdinova, T.; Ismailova, A.I.; Muranova, L.N.; Gainutdinov, K.L. Effects of preliminary administration of haloperidol in low doses on the effects of haloperidol on behavioral reactions and command neuron membrane potential in edible snail. Bull. Exp. Biol. Med. 2009, 148, 754-757. [CrossRef] [PubMed]

49. Epstein, O.I.; Sherstoboev, E.Y.; Martyushev-Poklad, A.V.; Dugina, Y.L.; Sergeeva, S.A.; Dygai, A.M. Dose-dependent effects and specificity of action of antibodies to endogenous regulators in ultralow doses. Bull. Exp. Biol. Med. 2004, 137, 460-462. [CrossRef] [PubMed]

50. Petrov, S.I.; Epstein, O.I. Effect of Potentiated Solutions on Mercury (II) Signal in Inversion Voltammetry. Bull. Exp. Biol. Med. 2003, 135 (Suppl. 7), 99-101. [CrossRef] [PubMed]

51. Galimov, E.M. The Phenomenon of Life: Between Balance and Nonlinearity. Origin and Principles of Evolution; Editorial URSS: Moscow, Russia, 2006; p. 256.

52. Gavrilova, E.S.; Bobrovnik, S.A.; Sherriff, G.; Myslivets, A.A.; Tarasov, S.A.; Epstein, O.I. Novel approach to activity evaluation for release-active forms of anti-interferon-gamma antibodies based on enzyme-linked immunoassay. PLoS ONE 2014, 9, e97017. [CrossRef] [PubMed]

53. Smith, S. Elektromagnitnaya bioinformaciya i voda. Bull. Biophys. Med. 1994, 1, 3-13.

54. Sudakov, K.V. Informacionnye svojstva funkcionalnyh sistem teoreticheskie aspekty. Vestn. Ross. Akad. Med. Nauk. 1997, 12, 4-19.

55. Gabor, D. A new microscopic principle. Nature 2012, 161, 777-778. [CrossRef]

56. Pribram, K.H. Languages of the Brain: Experimental Paradoxes and Principles in Neuropsychology; Prentice-Hall: Englewood Cliffs, NJ, USA, 1971; p. 432.

57. Anokhin, P.K. Ocherki po Fiziologii Funkcionalnyh Sistem; Meditsina: Moscow, Russia, 1975; p. 477.

58. Sudakov, K.V. Golograficheskij princip sistemnoj organizacii processov zhiznedeyatelnosti. Uspekhi Fiziol. Nauk 1997, 28, 3-32.

59. Witkop, B. Paul Ehrlich and His Magic Bullets-Revisited. Proc. Am. Philos. Soc. 1999, 143, 540-557. [PubMed]

60. Gurvich, A.G. Teoriya Biologicheskogo Polya; Sovetskaya Nauka: Moscow, Russia, 1944; p. 156.

61. Ezkurdia, I.; Juan, D.; Rodriguez, J.M.; Frankish, A.; Diekhans, M.; Harrow, J.; Vazquez, J.; Valencia, A.; Tress, M.L. Multiple evidence strands suggest that there may be as few as 19,000 human protein-coding genes. Hum. Mol. Genet. 2014, 23, 5866-5878. [CrossRef] [PubMed]

62. Kellis, M.; Wold, B.; Snyder, M.P.; Bernstein, B.E.; Kundaje, A.; Marinov, G.K.; Ward, L.D.; Birney, E.; Crawford, G.E.; Dekker, J.; et al. Defining functional DNA elements in the human genome. Proc. Natl. Acad. Sci. USA 2014, 111, 6131-6138. [CrossRef] [PubMed]

63. Pray, L.; Zhaurova, K. Barbara McClintock and the discovery of jumping genes (transposons). Nat. Educ. 2008, 1, 169.

64. Burnet, F.M. The Integrity of the Body: A Discussion of Modern Immunological Ideas; Harvard University Press: Cambridge, UK, 1962; p. 189.

65. Tverdislov, V.A.; Malyshko, E.V.; Ilchenko, S.A. From autowave mechanisms of self-assembly to molecular machines. Bull. Russ. Acad. Sci. Phys. 2015, 79, 1516-1520. [CrossRef]

(C) 2018 by the author. Licensee MDPI, Basel, Switzerland. This article is an open access article distributed under the terms and conditions of the Creative Commons Attribution (CC BY) license (http:/ / creativecommons.org/licenses/by/4.0/). 